ones-the viruses - which hover between the living and the dead. It is clear that the species concept in microbiology takes on a somewhat different meaning from that which it carries in the case of the higher organisms, and a reference to volume 6 of Rabenhorst's Kryptogamen-Flora, where recorded species of Phyllostica occupy 155 pages and those of Phoma 181 pages, illustrates the point. It is sometimes tempting to wonder whether, in many cases, there is any significant difference other than the host plant on which the species is recorded. It is also tempting to wonder whether a micro-organism, with its habit of physiological specialization and its aptitude for producing physiological races, behaves "as if inerease of appetite had grown by what it fed on". If this book does anything further it shows the need for more taxonomy and, in particular, more experimental taxonomy, and its reading will be well worth while for all postgraduate and research classical biologists.

The volume attains the high standard of production expected from Academic Press: the text is extremoly free from typographical errors and only two cases of mis. spelling were detected. Arthor E. MusketT

\section{VARIABILITY OF SPONGES}

\section{A Revision of the Classification of the Calcareous Sponges}

With a Catalogue of the Specimens in the British Museum (Natural History). By Dr. Maurice Burton. Pp. $v+693$. (London: British Museum (Natural History), 1963.) $300 s$.

WHE systematics of sponges are notoriously difficult. Breeding experiments for the present are out of the question, so that one's concept of a species must depend. on the general form, histology, spicule characteristics, development, and habitat-preferences of the animals concermed. For the great majority of the species hitherto described, however, information is only available regarding the form and skeleton, both of which can show great variation. This is clear from Dr. Burton's book, which is undoubtedly a major contribution to our knowledge of the systematics of sponges.

The book is divided into four main sections. The first includes observations on the range of variation in some common littoral species. Even in the same individual the spicules may vary widely in form and size, while the canal system may assume either the syconoid, grantioid or leuconoid arrangement. Using knowledge of the variability thus gained, Burton examines the genera hitherto recognized and reduces their number from 55 to 22 . He then lists the previously accepted species, giving each the equivalent specific name in his revised classification. Of the original 623 species (including 12 varieties) only 47 (48, according to Burton) remain.

Such extensive lumping will be considered by many to be unwarranted at the present state of knowledge. Can one be certain that the range of variation found for one species is equally applicable to another? Might not specimens with roughly similar spiculation and living in the same locality yet be found to differ in their development or habitat-preferences? Is it justifiable to ignore the position of the nucleus (apical or basal) in the choanocytes because there is more doubt about its taxonomic value than with the spicule characters (p. 31)? By so doing, Burton is able to lump together under Leuconia barbata several former species with apical nuclei and several with basal nuclei. To what extent does hybridization between species obscure the estimation of their variability? When Sycon ciliatum, Leuconia fistulosa and intermediate forms were discovered growing closely together, Burton regarded this as evidence for the variability of the former species, yet hybridization might conceivably have been involved. Only by growing regenerated portions of the same sponge in different environmental conditions can one obtain a satisfactory estimate of the possible range of variation for a given genotype.

The second section presents the systematic account of the Calcarea as understood by Burton. Apart from the great reduction in number of species, one can criticize his definition of the Homocoelidae, namely, "Calcarea having the whole endosomal cavity (or cloaca) . . . lined by collared cells". This is inexact, since choanocytes are lacking at the distal ends of the cloacal tubes.

The third and fourth sections will be of great value to future taxonomists. The latter is a catalogue of specimens and slides in the British Museum (Natural History) collection, while the former comprises brief diagnostic descriptions, often illustrated, and references for all the hitherto recognized species, grouped according to Burton's elassification. Here, it would have been helpful if the author had indicated the precise source of the descriptions under each species, so that the reader could check and amplify them if necessary. Thus, under Leucosolenia variabilis, the spicule characters appear to have been derived at second-hand from Arndt's Die Tierwelt der Nord-und Ostsee, Porifera (1935), for the same mistake is found when one compares the widths of the rays of the triradiates with those given in Minchin's original description. Information provided by Minchin on the range of variation in this species has been excluded.

The bibliography is complete up to the year 1953, but suffers from one defect, in that where several publications by the same author appeared in the same year no attempt is made to distinguish between them. Also the reference to Burton (1931) (p.5) does not appear in the list.

While Dr. Burton's simplified classification will be regarded by many as premature, there can be no doubt that he has produced a remarkable book; one which will be a starting point for future revisions of the classification for many years to come. W. CLIFFord Jones

\section{AGRICULTURAL PESTS}

Pests of Field Crops

By F. G. W. Jones and Margaret G. Jones. Pp. viii + $406+32$ plates. (London: Edward Arnold (Publishers), Ltd., 1964.) 50s. net.

$\mathrm{M}$ ORE than a century ago, John Curtis wrote the first comprehensive practical book on British farm pests. He dealt mainly with insects but also devoted space, proportionate to existing knowledge, on nematode, molluscan and other pests of farm land and farm stores. In Pests of Field Crops, Mr. and Mrs. Jones have produced a present-day 'Curtis'; while their book is intended for students and is concerned mainly with the animals which annoy the British farmer, they draw fully on examples from Europe and elsewhere to illustrate appropriate points. While emphasizing for each species the importance of field ecology and natural control, the authors give full consideration to chemicals and the overall coverage is comprehensive and well illustrated. There the similarity ends, because 'Curtis' was written at a lower level of tech. nical sophistication when man and agriculture were accepted as part of Nature; Jones and Jones, in the second line of their first chapter, define agriculture as "interfering with nature".

So the tone of the book is set: pests are animals in the wrong place and must be eliminated, provided that man is not inconvenienced by pesticide residues in the process. With such an end in view the student must be taught the fundamentals of population dynamies and have a good grounding in ecology. By the time the reader has finished the nine pages of Chapter 1 his appetite is whetted for more information on what constitutes a pest, but instcad he is given 24 pages of elementary morphology in Chapter 